\title{
Synoptic Characteristics of Surge-Producing Extratropical Cyclones along the Northeast Coast of the United States
}

\author{
ARIELle J. CATALANO \\ Department of Environmental Sciences, Rutgers, The State University of New Jersey, New Brunswick, New Jersey
}

ANTHONY J. BROCCOLI

Department of Environmental Sciences, and Institute for Earth, Ocean, and Atmospheric Sciences, Rutgers, The State University of New Jersey, New Brunswick, New Jersey

(Manuscript received 4 May 2017, in final form 23 October 2017)

\begin{abstract}
Extratropical cyclones (ETCs) are responsible for most of the large storm-surge events in the northeastern United States. This study uses the ECMWF atmospheric reanalysis of the twentieth century (ERA-20C) and NOAA tide gauge data to examine the local, regional, and large-scale atmospheric circulation accompanying the 100 largest ETC-driven surge events at three locations along the northeastern coast of the United States: Sewells Point (Norfolk), Virginia; the Battery (New York City), New York; and Boston, Massachusetts. Results from a $k$-means cluster analysis indicate that the largest surges are generated when slowly propagating ETCs encounter a strong anticyclone, which produces a tighter pressure gradient and longer duration of onshore winds. The strength of the anticyclone is evident in the middle and upper troposphere where there are positive 500-hPa geopotential height anomalies overlying the surface anticyclone for the majority of clusters and nearly all of the five biggest surge events. Multiple clusters feature a slower-than-average storm and a strong anticyclone, indicating that various circulation scenarios can produce a large storm surge. This favorable environment for large surge events is influenced by well-known modes of climate variability including El Niño, the Arctic Oscillation (AO), the North Atlantic Oscillation (NAO), and the Pacific-North American (PNA) pattern. ETCs are more likely to produce a large surge during El Niño conditions, which have been shown to enhance the East Coast storm track. At Boston and the Battery, maximum surge occurs preferentially during the positive phase of PNA and the negative phases of AO/NAO.
\end{abstract}

\section{Introduction}

Severe coastal storms devastate communities around the world, with significant socioeconomic impacts in heavily populated areas. These storms possess strong winds and heavy precipitation, which cause widespread flooding, property damage, and loss of life. For instance, Hurricane Sandy in 2012 produced the largest storm surge (and storm tide) on record at New York City, New York (Table 1), with severe impacts to life and property. Although Sandy was the largest surge event, the majority of surges in the northeastern United States are generated by extratropical cyclones (ETCs) rather than tropical systems.

For example, ETCs have been responsible for 88 of the 100 largest storm-surge events at the Battery in New

Corresponding author: Arielle J. Catalano, aa1019@envsci. rutgers.edu
York City (Table 1). The duration, direction, and strength of low-level winds influence the storm surge produced as ocean waters are driven inland (Bernhardt and DeGaetano 2012). A notable extreme storm-surge event was the Great Appalachian Storm of November 1950 (Smith 1950), which produced gusts of more than $140 \mathrm{mi} \mathrm{h}^{-1}\left(63 \mathrm{~m} \mathrm{~s}^{-1}\right)$ and up to $50 \mathrm{in} .(127 \mathrm{~cm})$ of snowfall in the mid-Atlantic region of the United States. The Great Appalachian Storm produced a storm surge that was only $20 \%$ smaller than that of Hurricane Sandy (13\% smaller after removing the trend in sea level). The 1950 storm had a lower overall water level and caused less damage than Sandy because the greatest surge occurred close to low tide. The timing of this event in the tidal cycle was a matter of chance, and thus there is the possibility that ETCs could produce coastal impacts of similar magnitude to those produced by Sandy. Thus, understanding the climatological behavior (or "climatology") 
TABLE 1. Percentage of the 100 largest surge events at Sewells Point, the Battery, and Boston categorized by storm type (i.e., extratropical or tropical).

\begin{tabular}{lcc}
\hline \hline & Extratropical & Tropical \\
\hline Sewells Point & 71 & 29 \\
The Battery & 88 & 12 \\
Boston & 91 & 9
\end{tabular}

of ETC-driven surge events is important for evaluating the future risk of inundation events, particularly as sea level continues to rise.

Important influences on storm climatology in the northeastern United States include large-scale modes of climate variability (Grise et al. 2013). There has been extensive research on the impacts of El Niño-Southern Oscillation (ENSO) on ETCs and associated surge. ENSO warm events are positively correlated with storm surge $>0.3 \mathrm{~m}$ during the cool season as a result of the meridional displacement of the subtropical jet (Sweet and Zervas 2011), which enhances the East Coast storm track (Eichler and Higgins 2006). Colle et al. (2010) also found an influence of ENSO on observed climatological frequency of minor- and moderate-surge events at the Battery. Other large-scale teleconnection patterns may influence surge frequency, such as the Pacific-North American (PNA) pattern, Arctic Oscillation (AO), and North Atlantic Oscillation (NAO). The positive phase of PNA exhibits below-average geopotential heights over the eastern United States and is associated with an increase in deep-cyclone activity (Gulev et al. 2001). During a negative AO (also referred to as the Northern Hemisphere annular mode), there is a higher frequency of blocking days and frozen-precipitation events in the North Atlantic Ocean (Thompson and Wallace 2001). Negative NAO conditions are also associated with blocking episodes (Shabbar et al. 2001) as well as increased ETC frequency in the western North Atlantic (Teng et al. 2008) and greater storm-tide variability in the New York harbor (Talke et al. 2014).

We aim to expand on previous work by analyzing aspects of the large-scale atmospheric circulation associated with surge-producing ETCs. We will use observations collected from tide gauges to obtain the highest storm-surge levels at our chosen locations, and we use a reanalysis product to analyze accompanying atmospheric circulation for these events. First, local circulation patterns are clustered to observe similarities among development of large surge events at each location. Second, we explore relationships of surge events with modes of climate variability, which influence regional circulation features in the Northeast. Third, a statistical analysis of the conditional probability of surge given the large-scale atmospheric circulation is explored. Our focus will be on storm-surge events that occur in the northeastern United States, although the method could be applied elsewhere.

\section{Data and method}

The northeastern coast of the United States is the focus of this study because the influence of ETCs on storm surge relative to tropical cyclones is prominent in this region. The largest surge events produced by ETCs were selected by using NOAA tide gauge records (http://tidesandcurrents.noaa.gov) for three locations: Sewells Point (Norfolk), Virginia; the Battery (New York), New York; and Boston, Massachusetts. These locations were chosen for the length and completeness of records (1927-present, 1920-present, and 1921present, respectively). Mean sea level trends were removed from the observed water level, with detrending centered on the 19-yr epoch of 1983-2001, a datum to which gauge measurements are referenced. Surge residuals were calculated by then subtracting the astronomical tide, and the 100 largest surges associated with ETCs were retained. Large surge residuals are designated as surge events whether or not a well-defined cyclone is present, although for the vast majority of cases there is a storm in the vicinity. Storms are classified as tropical or extratropical on the basis of their properties at the time of maximum surge (verified using synoptic weather maps and the National Hurricane Center archive). Only separate storm systems are considered-if the same ETC or circulation pattern produces multiple large surges, duplicate values are discarded. Also, hybrid systems that were either in transition or considered to be tropical up to $18 \mathrm{~h}$ prior to a large storm surge (such as Hurricane Sandy) are removed from this study. Note that raw tide gauge records sometimes contain spurious data because of human or technical errors. We manually remove these portions at each location before detrending and performing additional analysis.

To investigate the historical climatology of surgeproducing ETCs, we require a relatively long dataset with high temporal and spatial resolution and homogeneity. Thus, we utilize the latest ECMWF atmospheric reanalysis of the twentieth century (ERA-20C), which has a horizontal resolution of approximately $125 \mathrm{~km}, 91$ vertical levels, and output spanning 1900-2010 (Poli et al. 2016), sampled at 6-h intervals (0000, 0600, 1200, 1800 UTC) for the purpose of this study. ERA-20C was chosen rather than the twentieth-century reanalysis produced by NOAA/CIRES because it has greater spatial resolution. Comparisons between CIRES and ERA-20C indicate strong similarities in the areas of interest, suggesting that 
TABLE 2. The 10 largest storm surges associated with an ETC (detrended for sea level changes), measured at the NOAA tide gauges in Sewells Point, the Battery, and Boston.

\begin{tabular}{|c|c|c|c|c|c|}
\hline \multicolumn{2}{|c|}{ Sewells Point } & \multicolumn{2}{|c|}{ The Battery } & \multicolumn{2}{|c|}{ Boston } \\
\hline Date (UTC) & Surge $(\mathrm{m})$ & Date (UTC) & Surge $(\mathrm{m})$ & Date (UTC) & Surge $(\mathrm{m})$ \\
\hline 030013 Nov 2009 & 1.657 & 200025 Nov 1950 & 2.400 & 040026 Feb 2010 & 1.912 \\
\hline 19007 Mar 1962 & 1.558 & 170011 Dec 1992 & 1.809 & 080030 Nov 1945 & 1.526 \\
\hline 02005 Feb 1998 & 1.503 & 140029 Mar 1984 & 1.587 & 020031 Oct 1991 & 1.488 \\
\hline 220028 Jan 1998 & 1.388 & 050010 Nov 1932 & 1.547 & 190029 Mar 1984 & 1.383 \\
\hline 120025 Oct 1982 & 1.357 & 210017 Nov 1935 & 1.478 & 000014 Apr 1961 & 1.381 \\
\hline 230026 Apr 1978 & 1.286 & 220013 Mar 1993 & 1.476 & 08007 Feb 1978 & 1.380 \\
\hline 080024 Jan 1940 & 1.210 & 10007 Nov 1953 & 1.459 & 020018 Nov 1935 & 1.350 \\
\hline 100029 Jan 1937 & 1.208 & 040027 Oct 1943 & 1.429 & 030015 Feb 1940 & 1.270 \\
\hline 110025 Jan 2000 & 1.200 & 020025 Jan 1979 & 1.418 & 190012 Nov 1968 & 1.238 \\
\hline 070012 Apr 1956 & 1.192 & 090031 Oct 1991 & 1.414 & 06003 Mar 1947 & 1.233 \\
\hline
\end{tabular}

our results are not sensitive to the choice of ERA-20C. Tide gauge data are hourly, and therefore the closest 6-hourly snapshot previous to the time of maximum surge for a given storm is designated as $t=0$. This choice is based on previous work that has shown that the maximum wind speed occurs prior to the peak of maximum surge (Colle et al. 2010). For consistency with the temporal duration of the ERA-20C dataset, surge events were selected for the period from the beginning of the tide gauge records through 2010. The 100 largest ETC surge events at Sewells Point, the Battery, and Boston range from 0.731 to $1.657 \mathrm{~m}, 0.896$ to $2.400 \mathrm{~m}$, and 0.800 to $1.912 \mathrm{~m}$, respectively. The 10 largest surge-producing ETCs at each location are listed in Table 2.

We employ $k$-means cluster analysis (MacQueen 1967) to explore natural subdivisions of the 100 largest surge events. The $k$-means method has been widely used in atmospheric science to analyze features such as storm tracks (Blender et al. 1997; Xia et al. 2013), seasonal wind events (Leckebusch et al. 2008; Burlando 2009; Clifton and Lundquist 2012), and associated atmospheric quantities such as geopotential height (Michelangeli et al. 1995), temperature, and precipitation (Whitfield et al. 2004).

We cluster SLP data because of their utility in depicting the location and intensity of ETCs. Because we are interested in the synoptic evolution of each ETC surge event, we cluster the combined set of SLP fields at $t=0$, $t=-6 \mathrm{~h}, t=-12 \mathrm{~h}$, and $t=-18 \mathrm{~h}$. We find our chosen time period of $18 \mathrm{~h}$ preceding a storm surge to be suitable for capturing cyclogenesis and the duration of low-level flow inducing the surge (particularly for slower storms with a larger fetch). The spatial domain used for clustering surrounds the East Coast and includes almost 650 grid points (Fig. 1). The domain is designed to include local atmospheric circulation essential to storm-surge development and exclude any extraneous features. Cluster analysis demonstrates some sensitivity to variations in the spatial region, but resulting cluster centroids that are based on alternate domains are very similar to those displayed in this paper.

SLP values at each grid point from all four 6-hourly snapshots are combined into a vector $\mathbf{x}$ for each surge event, creating an array of data for $k$-means cluster analysis. The algorithm partitions vectors into $K$ clusters by minimizing the sum $S$ over all clusters of the Euclidean distance of each vector $\mathbf{x}$ from its respective cluster centroid $m$ :

$$
S=\sum_{k=1}^{K} \sum_{i=1}^{N}\left(x_{i, k}-m_{k}\right)^{2}
$$

where $N$ is the length of vector $\mathbf{x}$ (which includes grid points from four SLP maps, resulting in approximately 2600 elements).

Several classification schemes of ideal cluster separation such as silhouette values and complete-linkage hierarchical clustering were considered in our subjective choice of cluster number (Kaufman and Rousseeuw 1990). These visualizations of the optimal cluster number use the Euclidean distance as a metric of dissimilarity and are therefore subject to further examination depending on the number of observations and the purpose of the analysis. In our study, these choices were made to avoid having clusters with too few storms (subjectively determined to be less than four). The optimal number of clusters for the 100 largest surge events at Sewells Point was chosen to be six, whereas seven clusters were chosen for the Battery and Boston. A visual inspection of individual surge events assigned to sparsely populated clusters (e.g., cluster 4 at Sewells Point) suggests that nearly all events are well represented by the centroid pattern and amplitude. One limitation is that the average pattern may not represent the synoptic evolution of a large surge event with unique characteristics such as unusual propagation or speed. One example is the "Perfect Storm" of October 1991, 


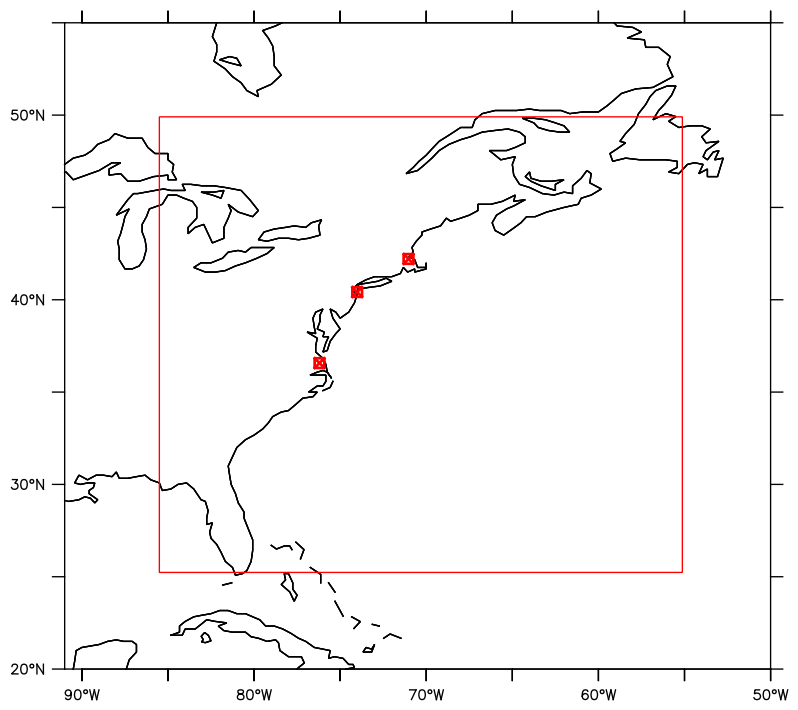

FIG. 1. The spatial domain in which $k$-means clustering is performed using ERA-20C sea level pressure data. Red points indicate the locations of the tide gauges at Boston, the Battery, and Sewells Point.

which was a late-season tropical cyclone in the North Atlantic Ocean that was absorbed by an ETC and propagated westward toward the northeastern coast of the United States. This unusual track coupled with a welldeveloped and intense cyclone produced a major storm surge at both Boston and the Battery (third and 10th highest, respectively). Although a few ETCs have distinct characteristics that differentiate them from other cyclones, particularly in synoptic evolution and propagation, there are similarities among surge-producing ETCs that a cluster analysis reveals.

The relationship between surge-producing ETCs and large-scale atmospheric circulation is explored. We analyze upper-level circulation and anomalies of geopotential height $(\mathrm{GPH})$ at $500 \mathrm{hPa}$ during maximum surge events. Anomalies are calculated by removing the 5-day running mean of the daily climatological average over the entire record. Surge-producing ETC events are also examined in the context of large-scale modes of climate variability including PNA, NAO, AO, and ENSO. Time series of indices of these modes of variability are available from the NOAA Climate Prediction Center and the KNMI Climate Explorer.

\section{Results}

\section{a. Cluster analysis of the 100 largest surge events}

Results from the cluster analysis for the 6-hourly evolution of surge-producing ETCs are displayed in Fig. 2 ordered from highest to lowest associated median surge (see Fig. 4, below). (Recall that SLP fields at $t=0$, $t=-6 \mathrm{~h}, t=-12 \mathrm{~h}$, and $t=-18 \mathrm{~h}$ were used to determine the clusters even though only the $t=0$ field for the cluster centroid is plotted.) Upper-air circulation influences the development and trajectory of surgeproducing ETCs, and therefore composite GPH fields for all clusters are presented in Fig. 3. There are a variety of attributes across all clusters. The average storm track may propagate along the East Coast, offshore, or from the Midwest, and some centroids exhibit a weaker cyclone that encounters a strong anticyclone as it progresses. At each location, a few clusters may appear to be similar, but there are subtle differences.

At the Battery, for example, clusters 3,5, and 7 depict a storm track with secondary cyclogenesis, and the isobars tend to be stretched out along the northwest-southeast axis (Fig. 2). There is a stronger anticyclone coupled with a weaker cyclone originating near the Gulf Coast in cluster 5, however, whereas cluster 7 exhibits pressure systems with the opposite intensity and the primary cyclone is near the Great Lakes at $t=-18$. Cluster 3 has a track that is similar to that of cluster 5 , although the average cyclone is stronger at $t=0$. Comparison of these three clusters at $500 \mathrm{hPa}$ indicates that the GPH anomalies and negative tilt are strongest for the deeper storm (cluster 7) and that the GPH field has a longer wavelength than in the other two clusters (Fig. 3). Cluster 5 has the shortest wavelength since a second trough is present around $48^{\circ} \mathrm{W}$. The positive and negative GPH anomalies have higher amplitudes in cluster 3 than in cluster 5 .

Other clusters at the Battery are more diverse. Cluster 6 depicts an average storm with a center jump at $t=-6$ and no anticyclone present to the north, whereas cluster 2 is a moderate cyclone with an East Coast storm track. Clusters 1 and 4 are both offshore systems, but the cyclone in cluster 4 is stronger and the anticyclone is weaker. The strength of these features is evident in GPH anomalies at $500 \mathrm{hPa}$ (Fig. 3).

A similar analysis of cluster features can be conducted at the other locations. At Sewells Point, clusters 1, 2, 3, and 6 feature the average storm advancing from the southwest to Virginia along the East Coast, although with anticyclones of varying intensity and location (Fig. 2). For example, cluster 1 features a strong anticyclone over Maine, whereas cluster 2 has a weaker anticyclone over the North Atlantic. GPH anomalies also differ in strength and location in these clusters, and the wavelength of the GPH field is shorter in cluster 3 than in cluster 2 (Fig. 3). The shape of the average storm in each centroid has a west-southwest-east-northeast orientation, whereas at Boston the systems are more symmetrical. ETCs at Boston are also generally better developed than at Sewells Point before and at the time of maximum surge. 


\section{Sewells Pt}

Battery
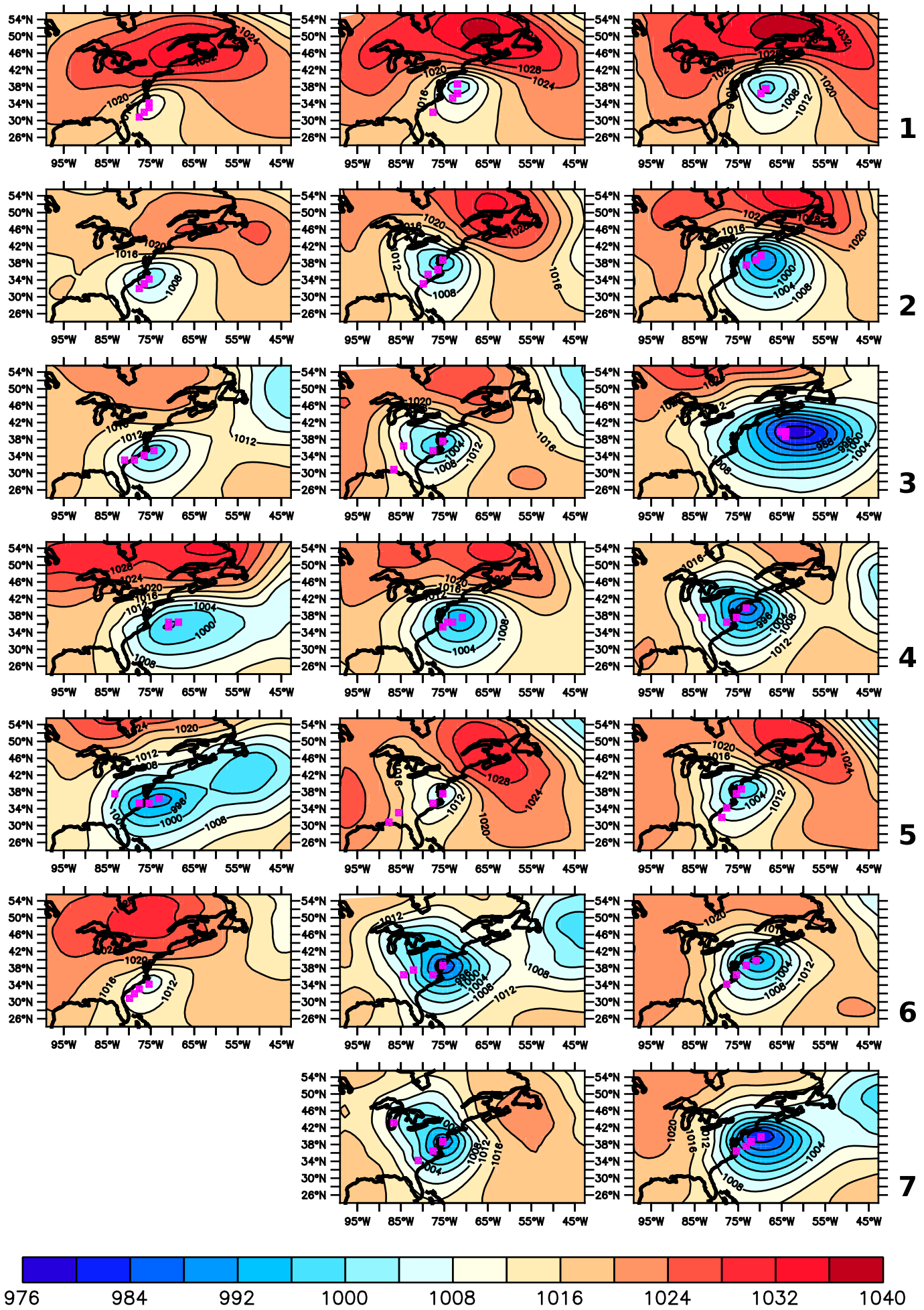

FIG. 2. Cluster centroids (numbered from top to bottom on the right-hand side) for the 100 largest surgeproducing ETCs at Sewells Point, the Battery, and Boston organized by decreasing associated surge values. Each map depicts the cluster centroid at the time before maximum surge $(t=0)$. Average cyclone centers at 0-, 6-, 12-, and 18-h lags $(t=0, t=-6, t=-12$, and $t=-18)$ are marked in magenta. 
Sewells Pt
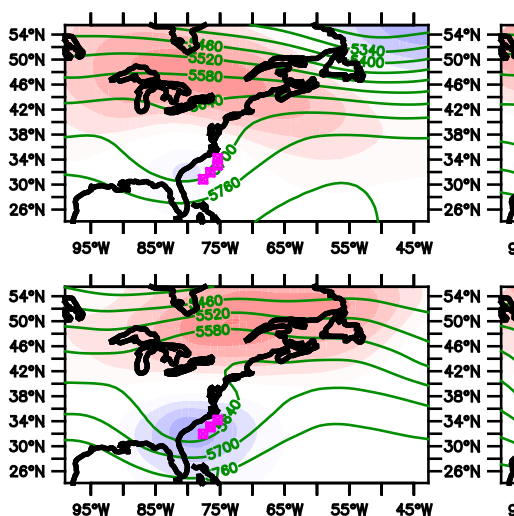

Battery

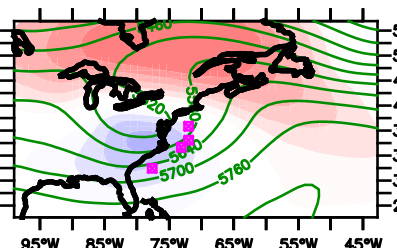

$95^{\circ} \mathrm{W} 85^{\circ} \mathrm{W} 75^{\circ} \mathrm{W} 65^{\circ} \mathrm{W}$ 5 $55^{\circ} \mathrm{W} 45^{\circ} \mathrm{W}$
Boston

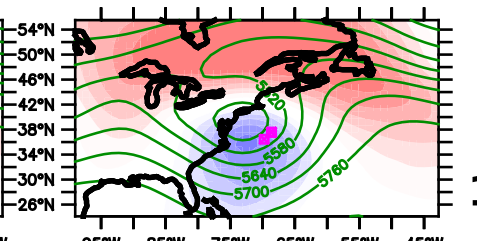

1

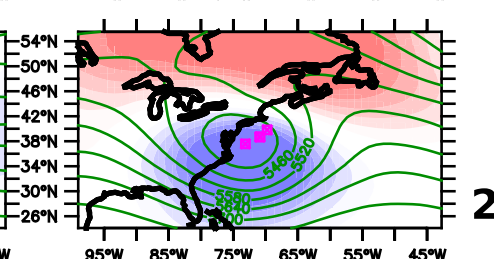

\section{2}
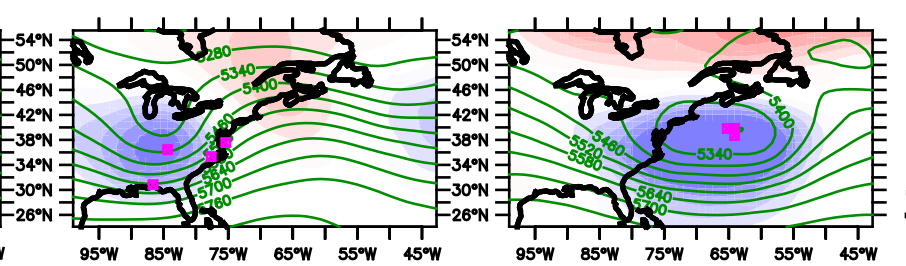

3

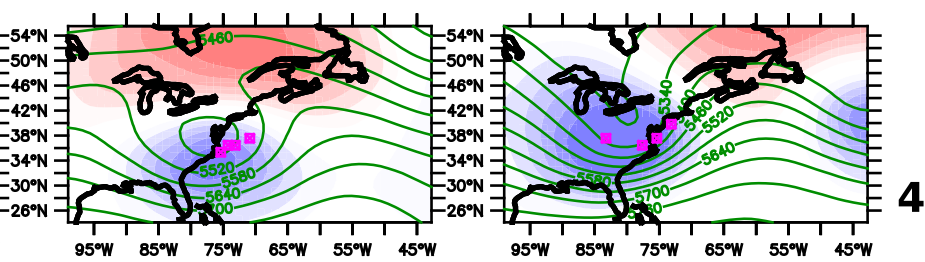

4
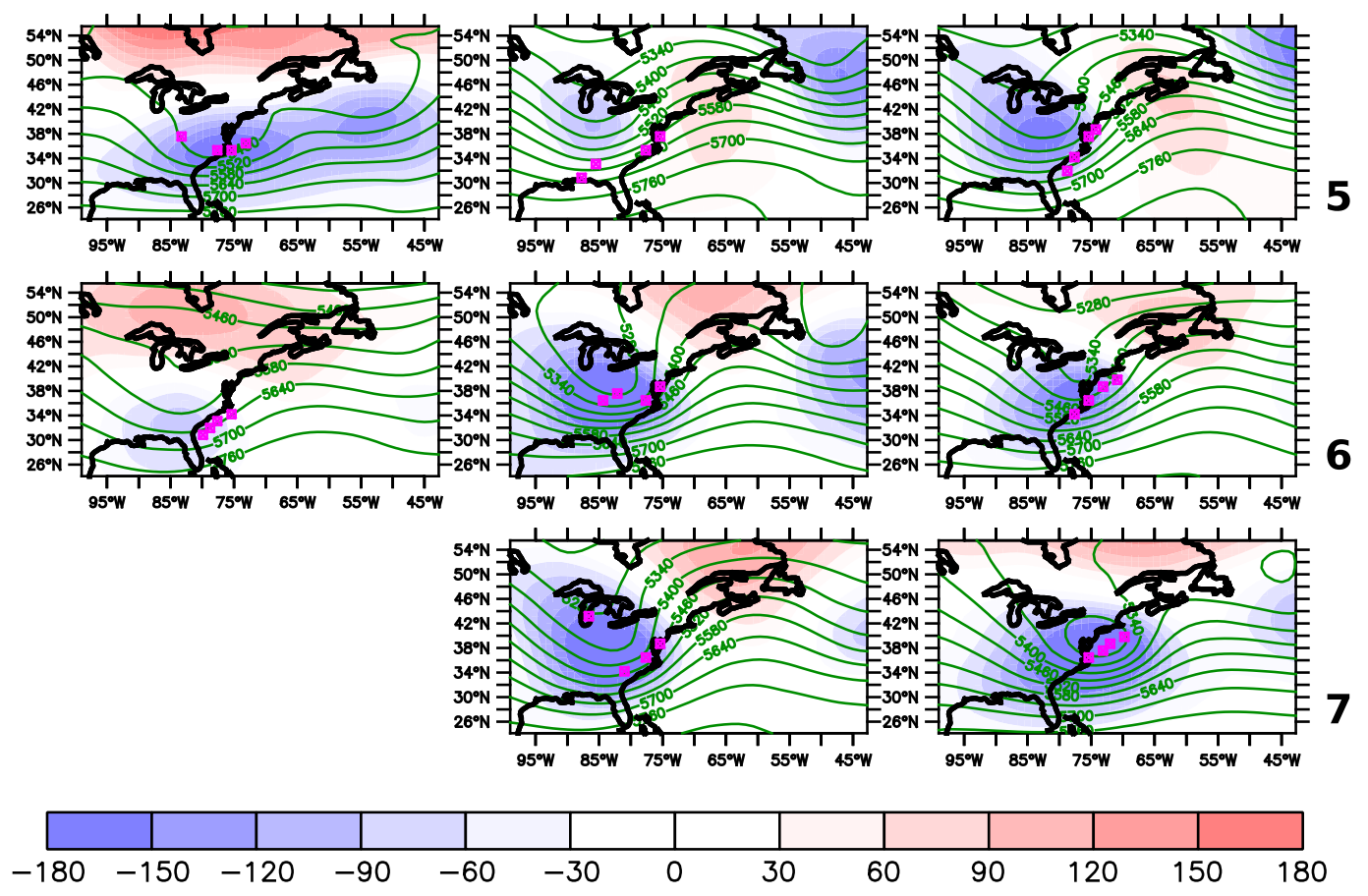

FIG. 3. Composite maps of atmospheric circulation at $500 \mathrm{hPa}$ at $t=0$ for the clusters in Fig. 2. Average cyclone centers at 0-, 6-, 12-, and 18-h lags $(t=0, t=-6, t=-12$, and $t=-18)$ are marked in magenta. Solid green contours represent $\mathrm{GPH}(\mathrm{m})$, and shaded regions are GPH anomalies $(\mathrm{m})$. 
TABLE 3. Average speed $\left(\mathrm{m} \mathrm{s}^{-1}\right)$ of cyclones in each cluster at Sewells Point, the Battery, and Boston. As discussed in the text, the average speed of all cyclones in the region surrounding these locations is $13.8 \mathrm{~m} \mathrm{~s}^{-1}$.

\begin{tabular}{lccc}
\hline \hline & Sewells Point & The Battery & Boston \\
\hline Cluster 1 & 9.2 & 10.4 & 7.9 \\
Cluster 2 & 6.6 & 10.3 & 8.8 \\
Cluster 3 & 11.3 & 15.9 & 7.1 \\
Cluster 4 & 9.7 & 8.6 & 14.0 \\
Cluster 5 & 11.1 & 14.2 & 14.2 \\
Cluster 6 & 9.5 & 13.8 & 14.1 \\
Cluster 7 & - & 15.0 & 10.2 \\
\hline
\end{tabular}

Table 3 lists the average speed of clustered storms, calculated using 6-hourly storm-track centers in the $18 \mathrm{~h}$ prior to maximum surge. A cyclone-detection algorithm developed at the Geophysical Fluid Dynamics Laboratory identifies cyclone centers using local minimum SLP, and centers are combined into a track through a trajectory analysis (Zhang et al. 2017; Zhao et al. 2009). To detect all cyclones, the requirement of warm core structure is deactivated. We also set the minimum lifetime requirement to $24 \mathrm{~h}$ and require a SLP minimum with at least one closed 4-hPa contour. The 6-hourly propagation speed is calculated using the difference between a cyclone's current position $\left(\mathbf{x}_{t=0}\right)$ and previous position $\left(\mathbf{x}_{t=-6}\right)$ measured along great circles. For the period 1920-2010, the average propagation speed for all cyclone tracks during the cold season (NovemberApril) in a region surrounding the three locations $\left(30^{\circ}-40^{\circ} \mathrm{N}, 82^{\circ}-64^{\circ} \mathrm{W}\right)$ is $13.8 \mathrm{~m} \mathrm{~s}^{-1}$.

For Sewells Point, all clusters have speeds slower than the average speed of all storm tracks (Table 3). Cluster 1 has the slowest average ETC propagation speed, with the centroid exhibiting a strong anticyclone (Fig. 2). Storms propagating more quickly near the Battery originate in the Midwest at $t=-18$ (clusters 3 and 7), and slow-moving systems remain offshore and are also inhibited by a strong anticyclone (clusters 1 and 4). In Boston, strong anticyclones are associated with a stationary cyclone offshore (clusters 1,2, and 3), whereas faster-than-average storms travel northeastward along the coast (clusters 4,5 , and 6).

The largest surge events are divided among the clusters, although some clusters contain more of the higher surges (Fig. 4). At Sewells Point, the cluster with the highest median surge (Fig. 4a) consists of a strong anticyclone and a slowly progressing cyclone (Table 3 ) that developed within $48 \mathrm{~h}$ of the maximum surge $(t=0)$. Cluster 6 has the lowest median surge, and all of the surge events in cluster 5 are below $1 \mathrm{~m}$. The two highest median surge values at the Battery (Fig. $4 \mathrm{~b}$ ) belong to clusters in which over $75 \%$ of the surge events are above
$1 \mathrm{~m}$. These centroids exhibit a strong anticyclone and a slow-moving cyclone with an East Coast storm track originating off the southeastern coast at $t=-18$ [a common storm track for large surge events that was also observed by Colle et al. (2010)]. The top three clusters at Boston also contain a system that is propagating more slowly than average (Fig. 4c, Table 3).

To focus on the most impactful events, ETCs associated with the five largest surges at each location are analyzed (Fig. 5). These surge events are associated with multiple clusters at each location, yet they are well represented by the associated centroid pattern (Fig. 2). The strongest surge-producing cyclones occur at Boston, where all five ETCs deepen to an average of $984.4 \mathrm{hPa}$ by $t=0$. The average central pressure of the top five storms at the Battery is $987.6 \mathrm{hPa}$, and at Sewells Point the average is $990.2 \mathrm{hPa}$. All but one of the surge events encounter a strong surface anticyclone to the north with positive $\mathrm{GPH}$ anomalies at $500 \mathrm{hPa}$. Also, these same ETCs propagate more slowly than average in the $18 \mathrm{~h}$ prior to maximum surge, with speeds ranging from 3.5 to $13.3 \mathrm{~m} \mathrm{~s}^{-1}$. This result agrees with our cluster analysis, which indicates that centroids of clusters with the highest surge events feature a slow-moving system to the south of a strong anticyclone. The similarity of the characteristics of the five largest surge events to those of the cluster centroids suggests that the cluster analysis is successfully identifying patterns that are associated with large surge events.

\section{b. Influence of large-scale atmospheric teleconnection patterns}

Atmospheric teleconnection patterns can affect the regional circulation associated with surge events. The influence of these patterns on surge events is assessed by examining the frequency distributions of $\mathrm{AO}, \mathrm{NAO}$, and PNA index values for the top 100 surge events at each location. Daily indices for AO, NAO, and PNA are obtained from the NOAA Climate Prediction Center (http:// www.cpc.ncep.noaa.gov/products/precip/CWlink/). These time series extend back to 1950, and therefore only the events occurring from 1950 to 2010 are included in this analysis (reducing the number of events to $\sim 70$ at each location). The majority of surge events at the Battery and at Boston occur during the negative phase of the $\mathrm{AO}$, whereas the relationship between surge events and the AO at Sewells Point is unclear (Fig. 6a). The influence of the $\mathrm{AO}$ on surge events increases from south to north, with nearly $75 \%$ of surge events at Boston occurring during a negative phase of AO. The relationship with NAO is similar although not as pronounced, and there is a positive shift in the frequency distribution at Sewells Point (Fig. 6b). The median PNA value is 

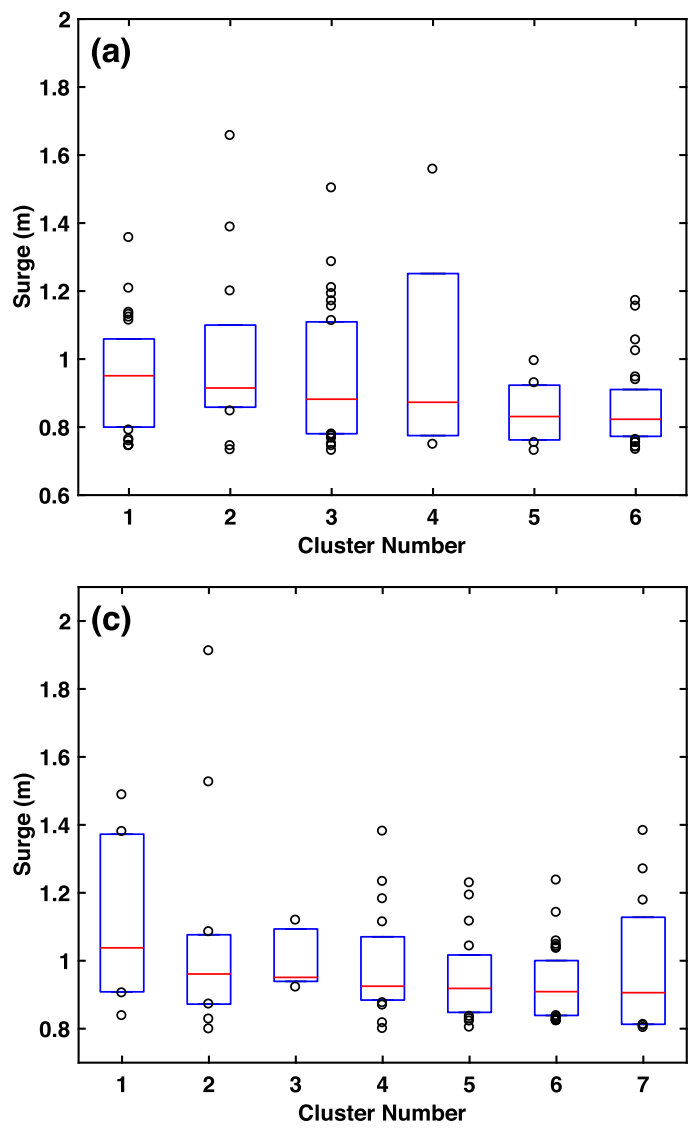

positive at all three locations (Fig. 6c), indicating that the top 100 surge events are more likely when the PNA is in its positive phase, which is associated with an amplified trough along the East Coast. The negative shift in $\mathrm{AO}$ and NAO frequency distributions during surge events extends to antecedent conditions for approximately 10 days, and the positive shift in PNA distributions persists for 5 days (not shown). This persistence is generally consistent with the time scales of $\mathrm{AO}, \mathrm{NAO}$, and PNA as determined by Feldstein (2000).

The statistical significance of these shifts in frequency distributions is analyzed using two methods: a two-tailed Student's $t$ test with a hypothesized population mean of index values equal to 0 , and a bootstrap analysis in which index values are randomly sampled $N$ times with replacement and averaged (where $N$ is the total remaining indices at each location for 1950-2010). This process is repeated 1000 times to generate a distribution of 1000 sample means, and a $95 \%$ confidence interval is determined as the 2.5 th and 97.5 th percentiles of this distribution. If a confidence interval does not include zero, the shift in a frequency distribution is deemed significant at the $5 \%$ level.

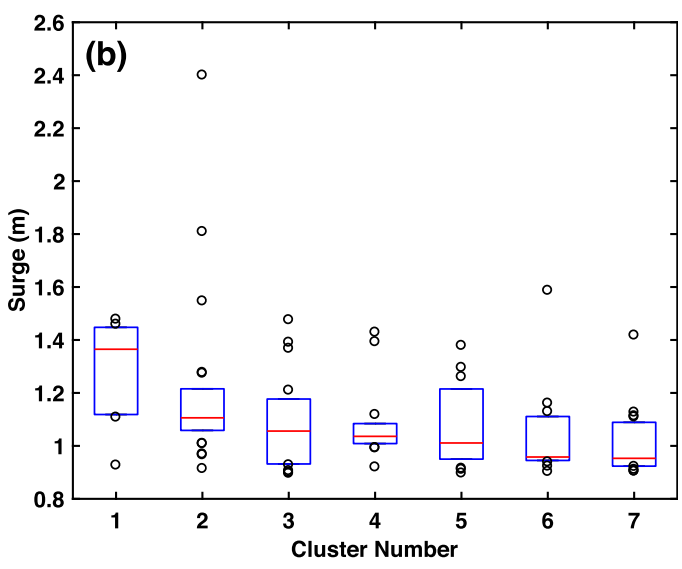

FIG. 4. Box-and-whisker plots of surge values (m) associated with the 100 largest ETC events at (a) Sewells Point, (b) the Battery, and (c) Boston organized by cluster. The top and bottom of the boxes represent the 75 th and 25 th percentiles, respectively, and red lines within each box indicate the median value. Open circles are surge values that lie outside the 25 th and 75 th percentiles.

Significant shifts in the frequency distributions of some teleconnection indices are consistently identified by both bootstrap and $t$-test results. The relationship between surge events and $\mathrm{AO}$ is statistically significant at the 5\% level at Boston and the Battery but not at Sewells Point. Statistically significant relationships with NAO and PNA are similarly confined to Boston and the Battery. The negative phases of NAO and AO are generally associated with anomalous positive GPHs over southeastern Canada, which are evident in the majority of clusters (Fig. 3) and the top five storms (Fig. 5) at Boston and the Battery.

Using a statistical-stochastic model that is based on reanalysis cyclone tracks, Hall and Booth (2017) determined that a negative NAO is associated with slower tracks, which supports our cluster-analysis results that centroids associated with the highest median surges exhibit slow-moving ETCs. Hall and Booth (2017) also observe that positive NAO is associated with enhanced rate of ETCs in the mid-Atlantic region. Their approach differs because they analyze extreme ETCs (a central SLP anomaly of $<-50 \mathrm{hPa}$ ), whereas this work focuses on surge-producing ETCs, which have a range of 


\section{Sewells Pt}

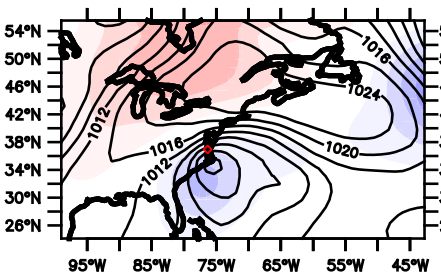

Nov 13, 2009

Cluster 2

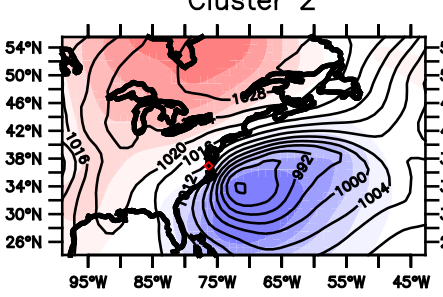

Mar 07, 1962

Cluster 4

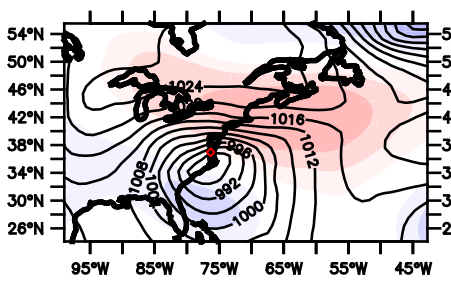

Feb 05, 1998

Cluster 3
Battery

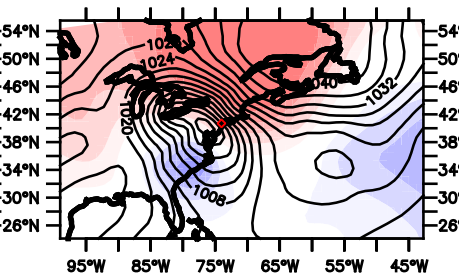

Nov 25, 1950

Cluster 2
Boston

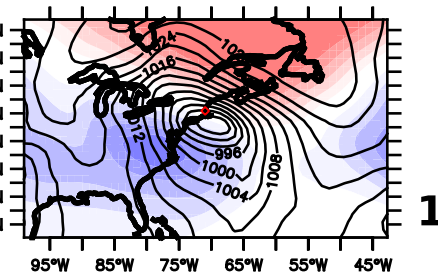

Feb 26, 2010

Cluster 2

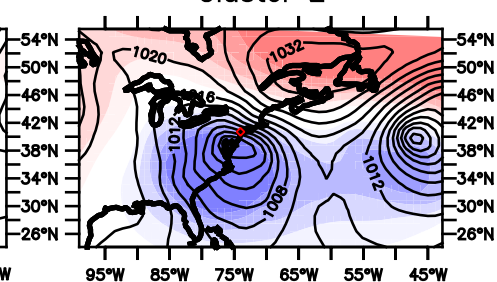

Dec 11, 1992

Cluster 2

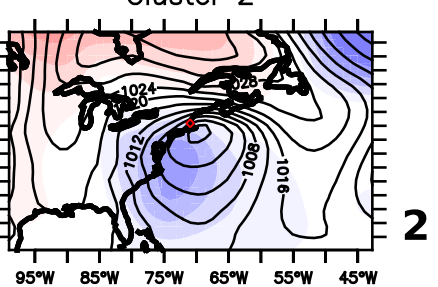

Nov 30, 1945

Cluster 2

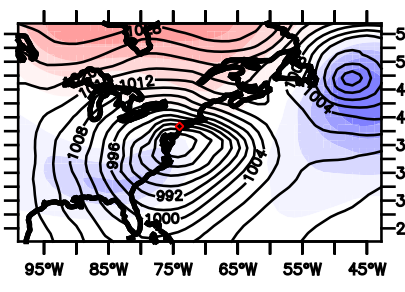

Mar 29, 1984

Cluster 6

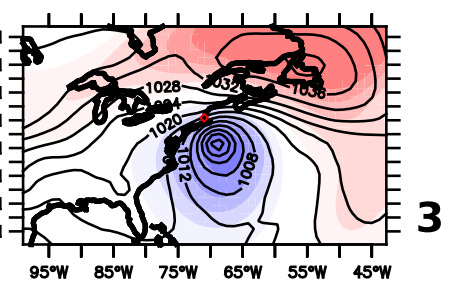

Oct 31,1991

Cluster 1

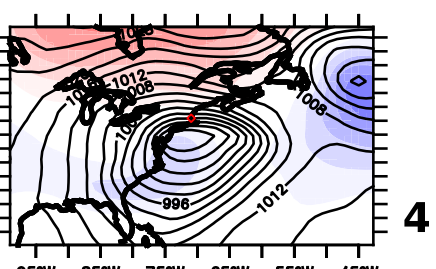

Mar 29, 1984

Cluster 7

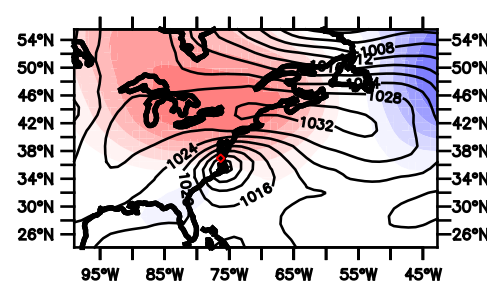

Oct 25, 1982

Cluster 1

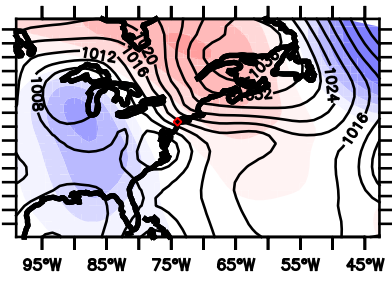

Nov 10, 1932

Cluster 2

\section{3}

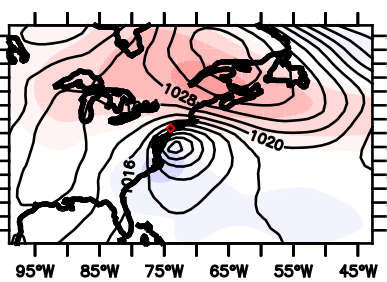

Nov 17, 1935

Cluster 1

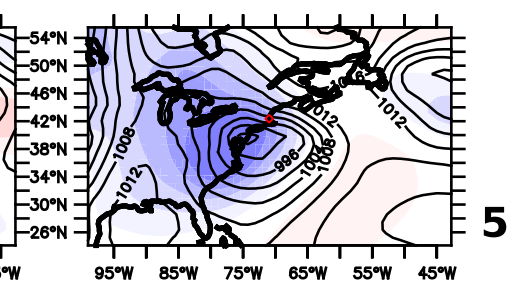

Apr 13, 1961

Cluster 4

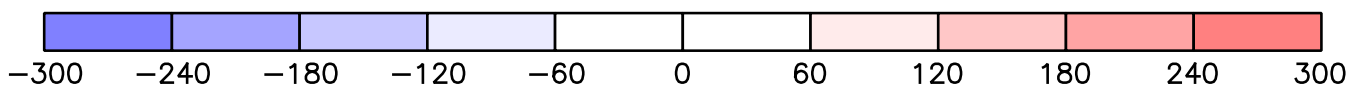

FIG. 5. Atmospheric circulation at time before maximum surge $(t=0)$ for the five largest surge events (decreasing from top to bottom) at Sewells Point, the Battery, and Boston. Solid black contours represent SLP (hPa), and shaded regions are GPH anomalies (m). 

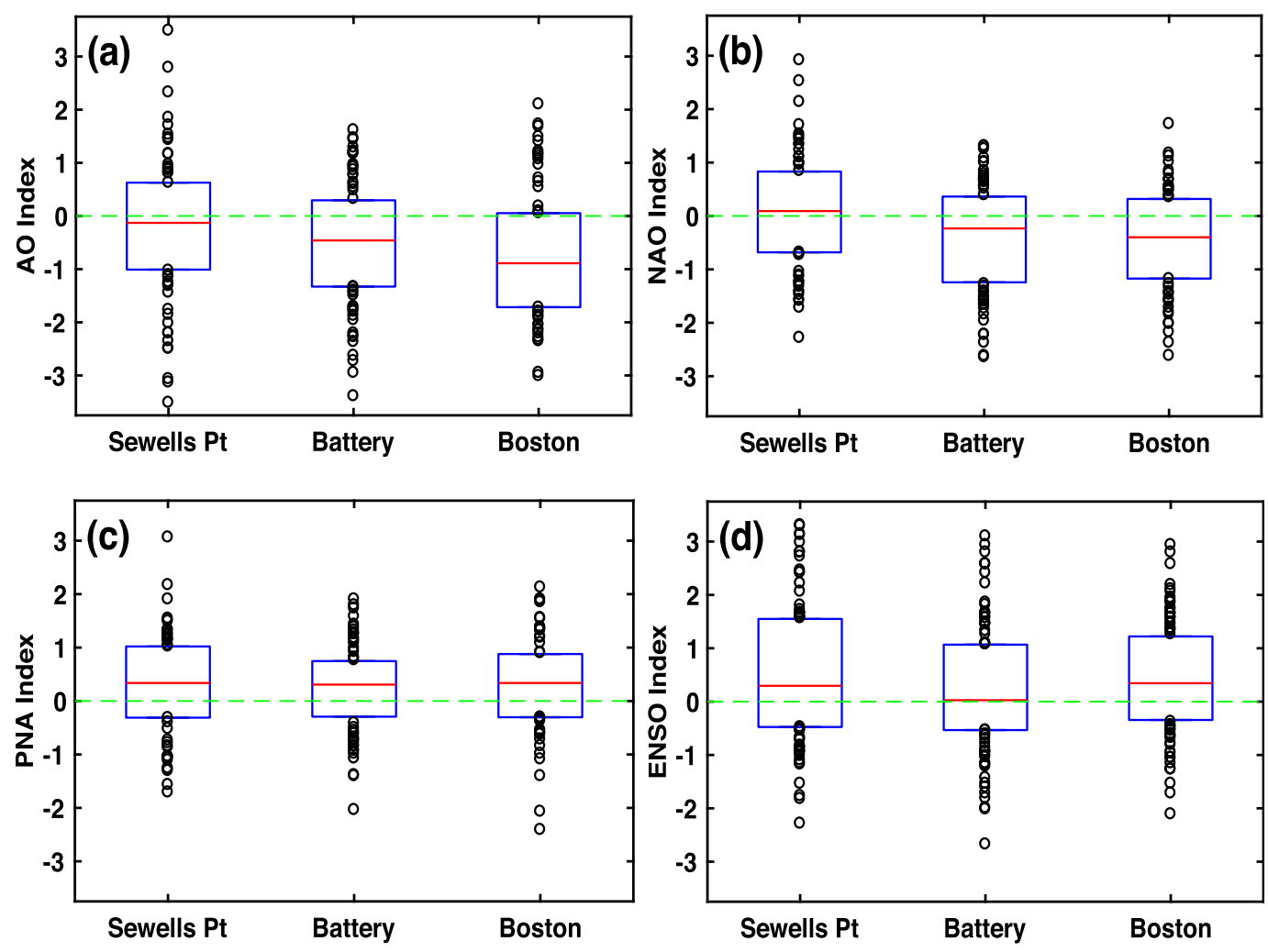

FIG. 6. Box-and-whisker plots of (a) AO, (b) NAO, (c) PNA, and (d) ENSO index values for the 100 largest surge events at Boston, the Battery, and Sewells Point.

intensities. A more extensive analysis of track properties for surge-producing ETCs would provide a better comparison with Hall and Booth (2017), but it is outside the scope of this study.

\section{c. Influence of ENSO}

We also analyze relationships with ENSO, a largescale pattern of climate variability that is associated with variations in SST in the tropical Pacific Ocean, which can influence atmospheric circulation in the North Atlantic (Sweet and Zervas 2011). A monthly Niño-3.4 index for ENSO spanning 1920-present is available from the KNMI Climate Explorer (https://climexp.knmi.nl/ start.cgi). Niño-3.4 is calculated using SST anomalies over a region of the Pacific Ocean, and the index is commonly used to monitor and analyze ENSO conditions (Trenberth and Stepaniak 2001; Chen et al. 2004).

Both the two-tailed $t$ test and bootstrap method reveal significance at the $5 \%$ level for the positive shifts in ENSO distributions at Boston and Sewells Point at $t=0$ (Fig. 6d). This result suggests that strong surge events at these locations are more likely during the positive phase of ENSO. The relationship between El Niño and large storm surge may be linked to a southward shift in the subtropical jet over the northeastern
United States, which increases storm activity along the East Coast (Sweet and Zervas 2011; Eichler and Higgins 2006). Hall and Booth (2017) also observe enhanced zonal propagation during ENSO, but they also observed a reduction in extreme ETC formation in the Northeast.

\section{d. Conditional probabilities of surge events}

In this section, we investigate the probabilities of substantial surge events conditioned upon different local and large-scale atmospheric circulation patterns as defined by the $k$-means cluster analysis and normalized teleconnection indices. To remove the influence of tropical cyclones, only cold season (November-April) events are considered. A small number of late-season tropical cyclones may remain after this seasonal filtering, but rigorous event-specific screening by manual evaluation of synoptic maps is impractical [e.g., 132860 maps (four maps per day $\times 365$ days per year $\times 91$ years in the longest tide gauge record)].

To understand the influence of local circulation patterns, we calculate the probability of a large surge ( $\geq 1 \mathrm{~m})$, a medium surge $(\geq 0.5 \mathrm{~m})$, and a positive surge $(\geq 0 \mathrm{~m})$ occurring for cyclones that most closely resemble a given cluster pattern (Table 4). Using all 
TABLE 4. Probability (\%) of surge $\geq 0,0.5$, and $1 \mathrm{~m}$ for all events assigned to previously determined clusters at Sewells Point, the Battery, and Boston.

\begin{tabular}{|c|c|c|c|c|c|}
\hline & Cluster & No. storms & Surge $\geq 0 \mathrm{~m}$ & Surge $\geq 0.5 \mathrm{~m}$ & Surge $\geq 1 \mathrm{~m}$ \\
\hline \multirow[t]{6}{*}{ Sewells Point } & 1 & 2011 & 83.1 & 6.7 & 0.5 \\
\hline & 2 & 1099 & 97.5 & 11.7 & 1.0 \\
\hline & 3 & 4739 & 86.4 & 4.7 & 0.4 \\
\hline & 4 & 186 & 100.0 & 36.0 & 5.4 \\
\hline & 5 & 1167 & 92.3 & 4.5 & 0.0 \\
\hline & 6 & 5746 & 73.8 & 3.4 & 0.1 \\
\hline \multirow{7}{*}{ The Battery } & 1 & 717 & 96.7 & 16.2 & 1.7 \\
\hline & 2 & 675 & 99.4 & 31.6 & 4.3 \\
\hline & 3 & 3451 & 93.0 & 8.5 & 0.4 \\
\hline & 4 & 912 & 97.4 & 21.3 & 2.0 \\
\hline & 5 & 1631 & 94.0 & 10.8 & 0.7 \\
\hline & 6 & 3202 & 87.3 & 4.6 & 0.3 \\
\hline & 7 & 5323 & 89.7 & 5.9 & 0.2 \\
\hline \multirow[t]{7}{*}{ Boston } & 1 & 404 & 96.0 & 17.3 & 1.7 \\
\hline & 2 & 311 & 99.4 & 44.7 & 3.9 \\
\hline & 3 & 687 & 99.0 & 14.1 & 0.4 \\
\hline & 4 & 1849 & 99.6 & 13.7 & 0.5 \\
\hline & 5 & 5114 & 90.7 & 5.2 & 0.2 \\
\hline & 6 & 10547 & 91.1 & 2.6 & 0.1 \\
\hline & 7 & 3089 & 94.0 & 5.1 & 0.2 \\
\hline
\end{tabular}

cold-season 6-hourly SLP data corresponding to the period of available tide gauge data, combined SLP maps (at $t=0, t=-6 \mathrm{~h}, t=-12 \mathrm{~h}$, and $t=-18 \mathrm{~h}$ ) are assigned to one of the previously determined clusters (Fig. 2) that they most closely resemble on the basis of the smallest Euclidean distance from each cluster's centroid. Note that if the distance to the centroid is greater than the maximum distance calculated for previously clustered ETCs (Fig. 2), the four-panel SLP map is not assigned to any cluster. These new collections of events, which are based on all possible cold-season SLP patterns, regardless of whether there is a cyclone present, is designated as "superclusters." At Sewells Point, the probability of a large or medium surge is greatest for superclusters 1,2 , and 4. These corresponding centroids to which surge values were assigned depict some of the slowest progressing systems for all centroids (Fig. 2). At the Battery, the corresponding centroids of the superclusters with the highest probabilities of a positive, medium, or large surge also exhibit a slow-moving cyclone as well as a strong anticyclone (Table 4; Fig. 2). In a similar way, centroids at Boston with a slower-than-average cyclone and strong anticyclone have the greatest probabilities of large or medium surges (Table 4; Fig. 2). Overall, the probability of a positive surge event corresponding to a particular supercluster ranges from $73 \%$ to $100 \%$ across all three locations.

We also explore the relative risk of a large $(\geq 1 \mathrm{~m})$ surge during negative and positive phases of PNA, $\mathrm{NAO}$, and $\mathrm{AO}$ in the cold season (Table 5). Normalized index values are binned into four intervals \{strong negative $(\leq-1)$, weak negative $(-1,0]$, weak positive $(0,1]$, and strong positive $(>1)\}$, and associated daily maximum surge values are calculated (1950-2010). Relative risk is defined as the ratio of the probability of surge events $\geq 1 \mathrm{~m}$ in each index interval to the overall probability of surge events of that magnitude. For example, the risk of a surge exceeding $1 \mathrm{~m}$ at the Battery is increased by a factor of 1.86 for $\mathrm{AO}$ indices $\leq-1$. An enhanced risk $(>2.00)$ occurs during the strong negative phase of NAO at all three locations and during the strong negative phase of AO at Sewells Point and Boston. There is also an enhanced risk of a large surge at Sewells Point for PNA indices in the strong positive interval. Conversely, there is a substantial reduction in the relative risk $(<0.50)$ of a large surge for NAO and $\mathrm{AO}$ indices in the strong positive interval at all three locations and for PNA indices in the strong negative interval at Sewells Point.

For the relative risk of a large surge during phases of ENSO, daily maximum surge values are assigned to corresponding monthly indices of Niño-3.4. At all three locations, the relative risk is greatest when Niño-3.4 index values are $>1$, and risk decreases at Boston and the Battery as indices become more negative (Table 5).

\section{Summary and discussion}

Our research expands on previous work concerning regional differences in ETC activity (Zhang et al. 2000; 
TABLE 5. Relative risk of surge events $\geq 1 \mathrm{~m}$ for PNA, NAO, AO, and ENSO index values within four intervals at Sewells Point, the Battery, and Boston. Relative risk is defined as the ratio of the probability of surge events $\geq 1 \mathrm{~m}$ in each index interval to the overall probability of surge events of that magnitude.

\begin{tabular}{llcccc}
\hline \hline & & Index $\leq-1$ & $-1<$ index $\leq 0$ & $0<$ index $\leq 1$ & Index $>1$ \\
\hline Sewells Point & PNA & 0.27 & 0.65 & 0.81 & 0.44 \\
& NAO & 2.17 & 1.37 & 0.66 & 0.00 \\
& AO & 2.04 & 1.08 & 0.33 & 0.48 \\
The Battery & ENSO & 0.40 & 1.05 & 0.99 & 2.68 \\
& PNA & 0.57 & 1.05 & 0.99 & 0.26 \\
& NAO & 2.51 & 0.96 & 1.28 & 0.35 \\
Boston & AO & 1.86 & 0.80 & 0.70 & 1.63 \\
& ENSO & 0.33 & 1.45 & 0.47 & 0.18 \\
& PNA & 0.70 & 1.18 & 0.45 & 0.19 \\
& NAO & 2.80 & 0.77 & 1.21 & 1.40 \\
\hline
\end{tabular}

Booth et al. 2015) by focusing on the local, regional, and large-scale atmospheric circulation properties for large surge events associated with ETCs. In the Northeast, coastal areas have higher exposure to storm surges associated with ETCs than with tropical cyclones (Booth et al. 2016; Orton et al. 2016). Therefore, we develop a framework for analyzing the synoptic climatology of surge-producing ETCs at three locations in the Northeast (Sewells Point, the Battery, and Boston), although our methods are applicable elsewhere. Notable results are summarized below.

- A set of distinct, local circulation patterns associated with the largest surge-producing ETCs in the northeastern United States can be identified using the $k$-means clustering algorithm.

- Cluster patterns associated with the highest median surge exhibit a slow-moving cyclone and an anticyclone to the north, which intensifies the pressure gradient and low-level winds. When considering all synoptic patterns that project onto these centroids, the probability of a medium $(\geq 0.5 \mathrm{~m})$ or large $(\geq 1 \mathrm{~m})$ surge is highest for surge events with these features.

- In a similar way, the majority of the largest five surge events at each location are deep cyclones to the south of a strong anticyclone. The strength of these features persists at $500 \mathrm{hPa}$, where there are positive GPH anomalies overlying the anticyclone.

- Large surge events occur preferentially during certain phases of large-scale atmospheric circulation patterns. At Boston and the Battery, AO and NAO are more likely to be negative and PNA is more likely to be positive, with these relationships being statistically significant at the 5\% level. Surge events are more likely to occur under El Niño conditions, with relationships being statistically significant at the $5 \%$ level at Boston and Sewells Point.
- Conditional probabilities of surge events also suggest that large surges are more common when teleconnection indices have a specific polarity. At all three locations, the relative risk of a large surge event occurring is greatest for NAO and AO indices in the strong negative interval $(\leq-1)$, and is smallest for positive indices.

The 100 largest surge events at Sewells Point, the Battery, and Boston are influenced by a variety of synoptic patterns, including intense cyclones, secondary cyclogenesis, and strong pressure gradients associated with relatively weak cyclones coupled with strong anticyclones. Across all locations, average surge levels associated with clustered ETCs are largest for SLP patterns that include a strong anticyclone to the north of a cyclone propagating more slowly than the average speed of $13.8 \mathrm{~m} \mathrm{~s}^{-1}$. In addition, superclusters (created with all 6-hourly SLP data for the cold season) that exhibit these features have the highest probability of experiencing a medium $(\geq 0.5 \mathrm{~m})$ or large $(\geq 1 \mathrm{~m})$ surge. This result suggests that strong anticyclones may be particularly important in the development of large stormsurge events by inhibiting ETC movement, thus causing a longer duration of onshore winds. Longer duration can lead to an accumulation of water over multiple tidal cycles, which augments surge height (Bernhardt and DeGaetano 2012). Conversely, clusters associated with the smallest average surge levels generally include fastmoving storms coupled with weaker anticyclones. Approximately $93 \%$ of the top five surge-producing ETCs moved more slowly than average up to $18 \mathrm{~h}$ prior to maximum surge and experienced GPH anomalies at $500 \mathrm{hPa}$ to the north of the storm. Although displaying some similarities, the five largest ETC-driven surge events are scattered among multiple clusters because of differences in storm development and trajectories. 
This finding indicates that many types of circulation patterns can influence local development of strong surges.

The tendency for the top 100 surge events at Boston and the Battery to occur during the negative phase of $\mathrm{AO}$ and NAO and the positive phase of PNA suggests the importance of the influence of these large-scale circulation patterns on storm tracks and persistence of anticyclones. Recent work by Munroe and Curtis (2017) also establishes a connection between these phases of PNA/NAO and surge duration at Duck, North Carolina. The negative phase of $\mathrm{AO} / \mathrm{NAO}$ is associated with a southward shift of the Atlantic storm track, which would increase the likelihood of cyclones passing to the south and east of Boston and the Battery. The negative phase of AO/NAO is also associated with more frequent blocking over Canada and the Atlantic Ocean (Shabbar et al. 2001), which may contribute to stormsurge events by slowing ETCs and tightening the pressure gradient to their north. The positive phase of PNA can be regarded as an intensification of the climatological trough over eastern North America in the middle and upper troposphere, which would enhance activity in the western portion of the Atlantic storm track.

Surge events at Boston and Sewells Point occur preferentially during El Niño conditions. Strong El Niños produce anomalous northeasterlies along the East Coast (Sweet and Zervas 2011), which is the predominant wind direction for the largest surge events at Boston and Sewells Point. Therefore, the East Coast track may be conducive to large surge development because of the orientation of low-level winds. Among the top 100 surge events, we do not find significant correlations between ENSO and storm-surge height. In fact, Sweet and Zervas (2011) determined that the correlation with ENSO was smaller for high surges at Boston, and Colle et al. (2010) observed a weaker relationship with moderate surge events at the Battery than with minor surges (although, for both studies, sample size was reduced at higher surge levels). Evaluating the potential nonlinearity in the strength of the correlation between ENSO and surge height would be beneficial and could be a focus of future work.

In attempting to quantify relationships between atmospheric circulation and storm-surge events, with storm surge defined as the difference between storm tide and astronomical tide, there may be an implicit assumption that the magnitude of the storm surge depends only on the large-scale meteorological conditions. There does exist a small, nonlinear interaction between astronomical tides and storm surge (Lin et al. 2012) that affects surge magnitude; storm surge may be larger for events occurring at low tide than for those occurring at high tide. This nonlinearity may be minimal at locations along the East Coast (Zhang et al. 2000), however, especially when its magnitude is compared with the large surge heights involved in this study.

An important concern going forward is the impact of anthropogenic climate change on inundation risks to coastal communities. The rate of increase in mean sea level over the past century contributed to an increase in 5- and 10-yr-return-period estimates of storm surge in the New York harbor region (Talke et al. 2014). Sea level rise is likely to be the dominant contributor to future changes in inundation risk (Roberts et al. 2017; Sweet et al. 2013; Lin et al. 2012), but quantifying such risk also requires a comprehensive understanding of the natural variations in surge-producing storms as well as an understanding of the influence of climate change on storm climatology. One limitation in understanding natural variations in ETC climatology is that highquality observations only extend back 100 years, and therefore they do not fully capture the range of events that may be possible. Long simulations from highresolution climate models, if they reproduce ETCs with sufficient fidelity, could be used to explore lessfrequent, high-impact surge events and to better constrain the tail of their frequency distribution. A similar approach that is based on physical modeling has been used for tropical cyclones (Lin et al. 2012; Orton et al. 2016). Exploring potential changes in surge-producing ETC climatology under a warming climate is also important, because changes in storm tracks or intensity could have disproportionate effects on distribution tails.

Acknowledgments. The authors thank three anonymous reviewers for constructive comments to improve this paper. The authors also thank C. Zervas for his invaluable assistance in obtaining and interpreting water-level data from NOAA/National Ocean Service, S. Decker for his insightful comments on an early draft of this manuscript, and B. Raney for advice on technical and computational matters. This research was supported by the William H. Greenberg Fellowship from Rutgers University, the State University of New Jersey, and by the National Science Foundation Earth System Modeling Program (OCE1049088).

\section{REFERENCES}

Bernhardt, J. E., and A. T. DeGaetano, 2012: Meteorological factors affecting the speed of movement and related impacts of extratropical cyclones along the U.S. East Coast. Nat. Hazards, 61, 1463-1472, https://doi.org/10.1007/ s11069-011-0078-0.

Blender, R., K. Fraedrich, and F. Lunkeit, 1997: Identification of cyclone-track regimes in the North Atlantic. Quart. J. Roy. Meteor. Soc., 123, 727-741, https://doi.org/10.1002/ qj.49712353910. 
Booth, J. F., H. E. Rieder, D. E. Lee, and Y. Kushnir, 2015: The paths of extratropical cyclones associated with wintertime high-wind events in the northeastern United States. J. Appl. Meteor. Climatol., 54, 1871-1885, https://doi.org/10.1175/ JAMC-D-14-0320.1.

$\longrightarrow, \ldots$, and Y. Kushnir, 2016: Comparing hurricane and extratropical storm surge for the mid-Atlantic and northeast coast of the United States for 1979-2013. Environ. Res. Lett., 11, 094004, https://doi.org/10.1088/1748-9326/11/9/094004.

Burlando, M., 2009: The synoptic-scale surface wind climate regimes of the Mediterranean Sea according to the cluster analysis of ERA-40 wind fields. Theor. Appl. Climatol., 96, 69-83, https://doi.org/10.1007/s00704-008-0033-5.

Chen, D., M. A. Cane, A. Kaplan, S. E. Zebiak, and D. Huang, 2004: Predictability of El Niño over the past 148 years. Nature, 428, 733-736, https://doi.org/10.1038/nature02439.

Clifton, A., and J. K. Lundquist, 2012: Data clustering reveals climate impacts on local wind phenomena. J. Appl. Meteor. Climatol., 51, 1547-1557, https://doi.org/10.1175/JAMC-D-11-0227.1.

Colle, B. A., K. Rojowsky, and F. Buonaito, 2010: New York City storm surges: Climatology and an analysis of the wind and cyclone evolution. J. Appl. Meteor. Climatol., 49, 85-100, https:// doi.org/10.1175/2009JAMC2189.1.

Eichler, T., and W. Higgins, 2006: Climatology and ENSOrelated variability of North American extratropical cyclone activity. J. Climate, 19, 2076-2093, https://doi.org/10.1175/ JCLI3725.1.

Feldstein, S. B., 2000: The timescale, power spectra, and climate noise properties of teleconnection patterns. J. Climate, 13, 4430-4440, https://doi.org/10.1175/1520-0442(2000)013<4430: TTPSAC $>2.0 . \mathrm{CO} ; 2$.

Grise, K. M., S.-W. Son, and J. R. Gyakum, 2013: Intraseasonal and interannual variability in North American storm tracks and its relationship to equatorial Pacific variability. Mon. Wea. Rev., 141, 3610-3625, https://doi.org/10.1175/ MWR-D-12-00322.1.

Gulev, S. K., O. Zolina, and S. Grigoriev, 2001: Extratropical cyclone variability in the Northern Hemisphere winter from the NCEP/NCAR reanalysis data. Climate Dyn., 17, 795-809, https://doi.org/10.1007/s003820000145.

Hall, T., and J. F. Booth, 2017: SynthETC: A statistical model for severe winter storm hazard on eastern North America. J. Climate, 30, 5329-5343, https://doi.org/10.1175/JCLI-D-16-0711.1.

Kaufman, L., and P. J. Rousseeuw, 1990: Finding Groups in Data: An Introduction to Cluster Analysis. John Wiley and Sons, 342 pp.

Leckebusch, G. C., A. Weimer, J. G. Pinto, M. Reyers, and P. Speth, 2008: Extreme wind storms over Europe in present and future climate: A cluster analysis approach. Meteor. Z., 17, 67-82, https://doi.org/10.1127/0941-2948/2008/0266.

Lin, N., K. Emanuel, M. Oppenheimer, and E. Vanmarcke, 2012: Physically based assessment of hurricane surge threat under climate change. Nat. Climate Change, 2, 462-467, https://doi.org/ 10.1038/nclimate1389.

MacQueen, J., 1967: Some methods for classification and analysis of multivariate observations. Proceedings of the Fifth Berkeley Symposium on Mathematical Statistics and Probability, Vol. 1, University of California Press, 281-297, http://projecteuclid.org/ euclid.bsmsp/1200512992.

Michelangeli, P.-A., R. Vautard, and B. Legras, 1995: Weather regimes: Recurrence and quasi stationarity. J. Atmos. Sci., 52, 1237-1256, https://doi.org/10.1175/1520-0469(1995)052<1237: WRRAQS $>2.0 . \mathrm{CO} ; 2$.
Munroe, R., and S. Curtis, 2017: Storm surge evolution and its relationship to climate oscillations at Duck, NC. Theor. Appl. Climatol., 129, 185-200, https://doi.org/10.1007/s00704-016-1770-5.

Orton, P. M., T. M. Hall, S. A. Talke, A. F. Blumberg, N. Georgas, and S. Vinogradov, 2016: A validated tropical-extratropical flood hazard assessment for New York harbor. J. Geophys. Res. Oceans, 121, 8904-8929, https://doi.org/10.1002/2016JC011679.

Poli, P., and Coauthors, 2016: ERA-20C: An atmospheric reanalysis of the twentieth century. J. Climate, 29, 4083-4097, https://doi.org/10.1175/JCLI-D-15-0556.1.

Roberts, K. J., B. A. Colle, and N. Korfe, 2017: Impact of simulated twenty-first-century changes in extratropical cyclones on coastal flooding at the Battery, New York City. J. Appl. Meteor. Climatol., 56, 415-432, https://doi.org/10.1175/JAMC-D-16-0088.1.

Shabbar, A., J. Huang, and K. Higuchi, 2001: The relationship between the wintertime North Atlantic Oscillation and blocking episodes in the North Atlantic. Int. J. Climatol., 21, 355-369, https://doi.org/10.1002/joc.612.

Smith, C. D., Jr., 1950: The destructive storm of November 25-27, 1950. Mon. Wea. Rev., 78, 204-209, https://doi.org/10.1175/ 1520-0493(1950)078<0204:TDSON >2.0.CO;2.

Sweet, W. V., and C. Zervas, 2011: Cool-season sea level anomalies and storm surges along the U.S. East Coast: Climatology and comparison with the 2009/10 El Niño. Mon. Wea. Rev., 139, 2290-2299, https://doi.org/10.1175/MWR-D-10-05043.1.

,,-- S. Gill, and J. Park, 2013: Hurricane Sandy inundation probabilities today and tomorrow [in "Explaining Extreme Events of 2012 from a Climate Perspective']. Bull. Amer. Meteor. Soc., 94 (9), S17-S20.

Talke, S. A., P. Orton, and D. A. Jay, 2014: Increasing storm tides in New York harbor, 1844-2013. Geophys. Res. Lett., 41, 31493155, https://doi.org/10.1002/2014GL059574.

Teng, H., W. M. Washington, and G. A. Meehl, 2008: Interannual variations and future change of wintertime extratropical cyclone activity over North America in CCSM3. Climate Dyn., 30, 673-686, https://doi.org/10.1007/s00382-007-0314-1.

Thompson, D. W. J., and J. M. Wallace, 2001: Regional climate impacts of the Northern Hemisphere annular mode. Science, 293, 85-89, https://doi.org/10.1126/science.1058958.

Trenberth, K. E., and D. P. Stepaniak, 2001: Indices of El Niño evolution. J. Climate, 14, 1697-1701, https://doi.org/10.1175/ 1520-0442(2001)014<1697:LIOENO>2.0.CO;2.

Whitfield, P. H., A. W. Hall, and A. J. Cannon, 2004: Changes in the seasonal cycle in the circumpolar Arctic, 1976-95: Temperature and precipitation. Arctic, 57, 80-93, https://doi.org/10.14430/arctic485.

Xia, L., H. von Storch, and F. Feser, 2013: Quasi-stationarity of centennial Northern Hemisphere midlatitude winter storm tracks. Climate Dyn., 41, 901-916, https://doi.org/10.1007/ s00382-012-1543-5.

Zhang, K., B. C. Douglas, and S. P. Leatherman, 2000: Twentiethcentury storm activity along the U.S. East Coast. J. Climate, $\mathbf{1 3}$, 1748-1761, https://doi.org/10.1175/1520-0442(2000)013<1748: TCSAAT $>2.0$.CO;2.

Zhang, W., G. A. Vecchi, G. Villarini, H. Murakami, R. Gudgel, and X. Yang, 2017: Statistical-dynamical seasonal forecast of western North Pacific and East Asia landfalling tropical cyclones using the GFDL FLOR coupled climate model. J. Climate, $\mathbf{3 0}$, 2209-2232, https://doi.org/10.1175/JCLI-D-16-0487.1.

Zhao, M., I. M. Held, S.-J. Lin, and G. A. Vecchi, 2009: Simulations of global hurricane climatology, interannual variability, and response to global warming using a $50-\mathrm{km}$ resolution GCM. J. Climate, 22, 6653-6678, https://doi.org/10.1175/ 2009JCLI3049.1. 